\title{
Why Do Policy Makers Stick to Inefficient Decisions?
}

\author{
Robert A.J. Dur \\ Tinbergen Institute, Erasmus University Rotterdam
}

This draft: June 1999

\begin{abstract}
This paper offers an explanation for why policy makers stick to inefficient policy decisions. I argue that repealing a policy is a bad signal to voters about the policy maker's competence if voters do not have complete knowledge about the effects of implemented policies. I derive the optimal policy maker's decision on continuation of a policy, assuming that voters' beliefs about the policy maker's competence are updated according to Bayes' rule. I show that if the policy maker cares sufficiently about reelection, he will never repeal a policy.
\end{abstract}

Keywords: reputation, elections, policy reversal.

JEL codes: D72, D78.

\section{Correspondence address:}

Robert A.J. Dur

Tinbergen Institute

Erasmus University Rotterdam

P.O. Box 1738

3000 DR Rotterdam

The Netherlands

e-mail: dur@few.eur.nl

phone \#: +31-10-408 8924

fax \#: +31-10-4089031

*I am grateful to Otto Swank for many useful suggestions. 


\section{Introduction}

The consequences of public policies are often surrounded with uncertainty. This uncertainty makes that even a highly competent policy maker sometimes implements an ineffective policy. A natural response to such a policy failure would be to repeal the policy and, possibly, to implement an other, hopefully more effective policy. In practice, however, policy makers are often quite reluctant to repeal a policy which they have implemented in the past, even if there are strong signals that the policy has been a failure.

This paper provides a rationale for this behaviour. I argue that repealing a policy is a bad signal to voters about the policy maker's competence. By repealing a policy, the policy maker confesses that he made a "wrong" decision, i.e. with hindsight he had better not implemented the policy. While making wrong decisions does not necessarily imply that the policy maker is incompetent, the occurrence of a policy failure increases the probability that he is incompetent. Repealing a policy thus damages the reputation of the policy maker and hence reduces his probability of reelection. I show that if the policy maker cares sufficiently about holding office, he will never repeal a policy, even if the policy does more harm than good. Electoral concerns may thus induce policy makers to stick to inefficient decisions.

Two assumptions play an important role in the analysis. First, I define the policy maker's competence as the probability that he designs an effective policy. This assumption implies that a policy failure is more likely to occur under an incompetent policy maker than under a competent policy maker. Alternatively, one could define a policy maker's competence as the quality of information about the effects of different policies the policy maker possesses before policy implementation. This would lead to exactly the same results as derived below.

Second, I assume that voters have imperfect knowledge about the effects of implemented policies. This assumption implies that the decision to repeal or continue a policy affects the 
voters' belief about the policy maker's competence. If voters know with certainty that a policy has been a failure, the decision to repeal the policy does not provide any additional information to voters about the effectiveness of the implemented policy, and hence does not affect the voters' belief about the policy maker's ability to design successful policies. Voters may be uncertain about the effects of implemented policies for several reasons. One reason might be that the variable the policy tries to affect is subject to exogenous shocks of which the size is not perfectly known by voters. One could think of policies aimed at reducing unemployment or boosting economic growth. Another reason might be that, although the policy is ex ante in many voters' interest, only a small proportion of the voters actually experience the effect of the policy, and thus only a small proportion of voters become wellinformed about the policy's effect. Public policies which provide the electorate with insurance may fall under this heading. Finally, voters may be imperfectly informed about an implemented policy because the policy only affects welfare under certain circumstances or after the elections. Examples include defence policy and public investment. The basic point of this paper is that office-motivated policy makers have an incentive to exploit the voters' uncertainty about policy effects for the purpose of reelection. Electoral concerns may cause a bias towards continuing policies, because from a decision to repeal a policy voters infer that the policy has been a failure.

Several studies have provided explanations for the persistence of inefficient policies. Femandez and Rodrik (1991) show that majority support for socially desired policy reform may lack due to uncertainty about the identity of winners and losers from policy reform. Alesina and Drazen (1991) provide a "war of attrition" explanation for why policy reform are delayed. Howitt and Wintrobe (1995) argue that political parties may not be willing to propose an efficient policy reform because they fear to end up with the other party's most- 
preferred policy, which is regarded as even worse than the status quo. Wirl (1991), building on Glazer and Grofman (1989), suggests that policy makers may want to change their public assessment of an implemented policy slowly in order to signal that they have stable preferences. More recently, Glazer and Hassin (1998) show that continuing inefficient policies may be part of an overall government's strategy to enhance people's confidence that government programs are lasting, which may increase the overall effectiveness of government policy. The explanation for the persistence of inefficient policies offered by this paper is complementary to these existing explanations.

The paper is closely related to the literature on elections and economic policy choice. Several papers have shown that electoral motives may distort policy choices. Rogoff (1990) has shown that if there is uncertainty among voters about the policy makers' competence in administering the public goods production process, the incumbent leader has an incentive to bias preelection fiscal policy toward easily observable consumption expenditures, and away from public investment. Others have focussed on situations where there is uncertainty among voters about the policy maker's preferences (Alesina and Cukierman, 1990) or about the working of the economy (Letterie and Swank, 1998, Schultz, 1996, Swank, 1998), or both (Harrington, 1993, Schultz, 1999). Most closely related to the present paper are Cadot and Sinclair-Desgagné (1992) and Swank (1999). Cadot and Sinclair-Desgagné (1992) show that if policy makers do not know whether they are competent or not, they may have an incentive to be overly "cautious" in deciding to take action or not. In particular, a policy maker may be tempted not to undertake actions which have a high informational content on his competence. As I will show in this paper, repealing a policy is such a strongly informative action and, in the spirit of Cadot and Sinclair-Desgagné's results, reputational concerns may induce policy makers not to repeal inefficient policies. Swank (1999) examines how policy makers' 
reputational concems affect the collection of information about policy effects before implementation. He shows that reputational concems may induce policy makers to gather insufficient information and to adopt secret decision procedures. Swank does not address the issue of whether or not to repeal implemented policies when they appear to be a failure.

The paper is organized as follows. The next section presents the basic model. In section 3 , I discuss the equilibria of the model. Three types of equilibria exist: a non-distortionary equilibrium (section 3.1), an equilibrium with distorted policy choice (section 3.2), and equilibria in mixed strategies (section 3.3). Which of those equilibria arises, depends critically on how much the incumbent cares about reelection relative to voters' welfare. Section 4 concludes with a summary and some directions for further research.

\section{The Model}

The model comprises two periods. At the beginning of each period, an incumbent politician designs or discovers a policy. The policy is either a "success" or a "failure", which is uncertain before implementation of the policy. If the policy is a success, voters' expected welfare increases by $b_{\mathrm{T}}$ per period, where the subscript denotes the period in which the policy was designed. A policy failure is, for simplicity, assumed to be costless, unless the policy is continued. Then voters' expected welfare decreases by $c_{\mathrm{T}}$ per period. Like all voters, the incumbent policy maker cares about policy outcomes in period 1 and 2. In addition, the policy maker receives "ego rents" of $X_{t}$ if in office in period t (cf. Rogoff, 1990). The utility function of the policy maker in office in period 1 is given by:

(1) $\quad U^{I}=\sum_{\mathfrak{t}=1}^{2}\left(V_{\mathfrak{t}}+e_{\mathfrak{t}} X_{\mathfrak{t}}\right)$ 
where $V_{\mathrm{t}}$ is the expected voters' welfare in period $\mathrm{t}, e_{1}=1$, and $e_{2}$ is either 0 or 1 , depending on whether or not the incumbent is reelected. Voters' expected welfare at the beginning of the first period is normalized to zero.

Before implementation, the incumbent is uncertain whether the policy he designed will be a success or a failure. The probability that the policy is a success depends on the policy maker's competence. Two types of policy makers exist: competent policy makers and incompetent policy makers. A competent (incompetent) policy maker faces a probability $p(q)$ that the policy he designed is a success, where $p>q$. Neither the policy maker himself, nor the voters know with certainty whether the policy maker is competent or incompetent. The prior probability that the incumbent in period 1 is competent is denoted by $\pi^{I}$, which is common knowledge.

After implementation, the policy maker, irrespective of his competence, receives a fully informative signal about the effect of the policy. Voters do not observe this signal. ${ }^{1}$ After receiving the fully informative signal, the policy maker decides either to continue or to repeal the policy. This decision is observed by voters who in response revise their belief about the policy maker's competence using Bayes' rule. The voters' posterior probability that the incumbent in period 1 is competent is denoted by $\hat{\pi}^{I}$.

At the end of the first period, elections are held in which two candidates, the incumbent and an opponent, compete for taking office in the second period. Voters vote for the candidate who is expected to deliver the highest welfare in period $2, V_{2}$. The identity of the opponent

\footnotetext{
${ }^{1}$ For simplicity, I restrict attention to the case wherein the incumbent becomes completely informed and voters remain completely uninformed about the effect of implemented policies. All the results carry over to the case wherein voters receive a noisy signal about the policy's effect (see the Appendix). Crucial for the results is that the policy maker has more information about the effect of implemented policies than the voters.
} 
becomes known just before the elections. ${ }^{2}$ The prior probability that the opponent is competent, which is denoted by $\pi^{0}$, is randomly drawn from $[0,1]$ according to the cumulative distribution function $G(\cdot):[0,1] \rightarrow[0,1]$. Thus, $G\left(\pi^{x}\right)$ denotes the probability that $\pi^{0}$ is smaller than $\pi^{x}$.

After the elections, the winning candidate takes office. As in period 1 , the incumbent in period 2 designs a policy at the beginning of the period. After implementation, he receives a fully informative signal about the effect of the policy, and decides either to continue or to repeal the policy. In addition, the incumbent in period 2 decides on continuation of the policy implemented in period 1 , unless this policy has been repealed in the previous period.

In summary, the sequence of events is as follows:

1. Nature chooses the identity of the incumbent in period 1 .

2. The incumbent designs and implements a policy.

3. The incumbent observes a fully informative signal about the effect of the implemented policy.

4. The incumbent chooses to continue or to repeal the policy.

5. Voters observe the incumbent's decision and revise the prior probability that the incumbent is competent.

6. Nature chooses the identity of the opponent.

7. Elections take place.

8. The winning candidate designs and implements a policy.

${ }^{2}$ This assumption is made in order to exclude cases in which the incumbent, when deciding on continuation of the implemented policy, is sure to win or lose the elections whichever decision he takes. In such cases, the incumbent's decision is of course not distorted by electoral motives. Altematively, one could assume that the voters' belief about the opponent's competence is not too far from the voters' belief about the incumbent's competence such that the incumbent's decision matters for the election outcome. 
9. The winning candidate observes a fully informative signal about the effect of the implemented policy (policies).

10. The winning candidate chooses to continue or to repeal the policy (policies).

11. The world ends.

\section{Equilibria}

In this section, I solve the model for Perfect Bayesian equilibria. In a Perfect Bayesian equilibrium, each players' strategy is optimal given the equilibrium strategies and beliefs of the other players, where the players' beliefs are updated according to Bayes' rule. To ensure time consistency, I start with the decisions taken in the second period.

The incumbent in period 2 makes two decisions. First, he decides to continue or to repeal the policy he has designed and implemented at the beginning of the second period. Second, he decides on the continuation of the policy implemented in period 1 , unless this policy has been repealed in period 1. Since the incumbent in period 2 does not face an election constraint, his decision to continue or repeal policies is not distorted by electoral motives. He simply maximizes $V_{2}$. Hence, he continues a policy if it is a success and repeals it if it is a failure.

In deciding their vote at the end of period 1 , voters compare expected utility under each of the two candidates. Since the incumbent and the opponent do not differ in their decisions on the continuation of policies, the only difference between the two candidates is their (expected) competence in designing a successful policy at the beginning of the second period. ${ }^{3}$ Voters

\footnotetext{
${ }^{3}$ In a multi-period framework without term limits, the opponent would have an advantage over the incumbent because only the latter has an incentive to distort the decision taken on continuation of the policy implemented in the first period. In a multi-period framework with a term-limit of two periods, the incumbent would have an advantage over the opponent since only the latter has an incentive to distort the decision taken on continuation of the policy implemented in the second period (see also Cadot and Sinclair-Desgagné, 1992).
} 
reelect the incumbent if:

$$
\hat{\pi}^{I} p b_{2}+\left(1-\hat{\pi}^{I}\right) q b_{2}>\pi^{O} p b_{2}+\left(1-\pi^{O}\right) q b_{2} \quad \Rightarrow \quad \hat{\pi}^{I}>\pi^{O}
$$

Hence, the incumbent is reelected if voters believe that he is more likely to be competent in designing policies than the opponent.

The voters' belief about the incumbent's competence, and thus the incumbent's probability to be reelected, may be affected by the decisions the incumbent makes in period 1 . The incumbent in period 1 makes one decision: after observing whether the policy he has implemented is a success or a failure, the incumbent decides either to continue or to repeal the policy. Since the incumbent cares about holding office, he takes into account the effect of his decision on his chances of reelection. Vice versa, when revising their belief about the incumbent's competence, voters realize that electoral concerns affect the incumbent's policy decision. In a Perfect Bayesian equilibrium, the incumbent's strategy is optimal given the equilibrium strategy and beliefs of the voters. In addition, the players' beliefs are updated according to Bayes' rule. In the remainder of this section, I show that three types of Perfect Bayesian equilibria exist, two in pure strategies and one in mixed strategies.

\subsection{Non-distortionary Equilibrium}

Let me start with, what might be called, the socially efficient strategy: the incumbent in period 1 continues the policy if he has observed that it is a success, and repeals it if he has observed that it is a failure. Suppose that voters believe that the incumbent follows this strategy. After observing the policy maker's decision, voters update their belief about the 
policy maker's competence using Bayes' rule. Thus, if the policy is continued, the posterior probability that the incumbent is competent is:

$$
\hat{\pi}_{c}^{I}=\frac{\pi^{I} p}{\pi^{I} p+\left(1-\pi^{I}\right) q} .
$$

If the policy is repealed, the posterior probability that the policy maker is competent is:

(4)

$$
\hat{\pi}_{r}^{I}=\frac{\pi^{I}(1-p)}{\pi^{I}(1-p)+\left(1-\pi^{I}\right)(1-q)} .
$$

Since $p>q$, it follows that $\hat{\pi}_{r}^{I}<\pi^{I}<\hat{\pi}_{c}^{I}$. Hence, continuing (repealing) the implemented policy increases (decreases) the voters' posterior probability that the incumbent is competent. What decision will the incumbent make, given these voters' beliefs? Suppose that the policy maker has observed that the policy is a success. Continuing the policy is preferred to repealing the policy if:

$$
2 b_{1}+\left[G\left(\hat{\pi}_{c}^{I}\right)-G\left(\hat{\pi}_{r}^{I}\right)\right]\left[X_{2}+\left(\hat{\pi}_{c}^{I}-\pi_{e}^{O}\right)(p-q) b_{2}\right]>0
$$

where $\pi_{e}^{0}$ is the expected value of the prior probability that the opponent is competent. The first term in (5) represents the effect of continuing the successful policy on welfare in period 1 and 2 , which is obviously positive. ${ }^{4}$ The second term represents the effect of the incumbent's decision on his probability of reelection, and thus on his expected utility in period 2. Recall that $G(\cdot)$ is the cumulative distribution function of $\pi^{O}$. Hence, using the result described by

${ }^{4}$ If repealing the policy in period 1 does not exclude implementing the policy again in period 2 , the first term in (5) is $b_{1}$ instead of $2 b_{1}$. This does not affect the results. 
(2) of the optimal voters' decision at the end of the period $1, G\left(\hat{\pi}_{c}^{I}\right)$ is the probability that the incumbent is reelected given the voters' posterior belief $\hat{\pi}_{c}^{I}$. Using (3) and (4), it follows that $G\left(\hat{\pi}_{c}^{I}\right)>G\left(\hat{\pi}_{r}^{I}\right)$, i.e. the probability of reelection is higher when the incumbent decides to continue the policy than when he repeals the policy, given the voters' beliefs. Therefore, provided that the incumbent expects to prefer reelection to losing the elections, ${ }^{5}$ the second term in (5) is also positive. Hence, if voters believe that the incumbent follows the socially efficient strategy, and the incumbent has observed that the implemented policy is a success, his optimal decision is to continue the policy.

When the policy maker has observed that the policy is a failure, repealing the policy is optimal if:

$$
c_{1}+\left[G\left(\hat{\pi}_{r}^{I}\right)-G\left(\hat{\pi}_{c}^{I}\right)\right]\left[X_{2}+\left(\hat{\pi}_{r}^{I}-\pi_{e}^{O}\right)(p-q) b_{2}\right]>0
$$

In contrast to condition (5), condition (6) is not always satisfied. The first term in (6) represents the benefit of repealing the policy. By repealing the policy, the cost of continuing a policy failure is avoided. This term is always positive. The second term in (6) is the effect of the policy maker's decision on his reelection chances, and thus on his welfare in period 2 . Repealing the policy hurts the reputation of the incumbent, and thus reduces his chances of reelection $\left[G\left(\hat{\pi}_{r}^{I}\right)<G\left(\hat{\pi}_{c}^{I}\right)\right]$. Provided that the incumbent expects to prefer reelection to losing the elections, the second term is negative. If the incumbent cares sufficiently about holding office ( $X_{2}$ is sufficiently high relative to voters' welfare in period 1 and 2), condition (6) is

${ }^{5}$ The incumbent may prefer to lose the elections if he cares little about being in office $\left(X_{2}\right.$ is low), and if the probability that the opponent is competent is much higher than his probability to be competent $\left(\pi^{O}\right.$ is much above $\hat{\pi}_{c}^{I}$ ). In that case, the incumbent's optimal decision in period 1 is also to continue the successful policy, and not to run for reelection at the end of the first period. 
violated. Then, the incumbent prefers to continue the unsuccessful policy, given the voters' beliefs. Therefore, the socially efficient strategy is a Perfect Bayesian equilibrium strategy only if $X_{2}$ is not too high such that condition (6) is satisfied.

\subsection{Equilibrium with Distorted Policy Choice}

Suppose now that voters believe that the incumbent always decides to continue the implemented policy, also when the policy is a failure. This might be called the office-seekers? strategy. If the incumbent follows this strategy, a decision to continue the implemented policy does not provide information about the effect of the policy to voters. Therefore, voters do not adjust their belief about the incumbent's competence in response to a decision to continue the policy; voters' posterior belief about the policy maker's competence is equal to their prior belief $\pi^{I}$. The incumbent himself, however, does update his belief about his competence, since he knows whether the policy he designed is a success or a failure. To derive under what conditions it is optimal for the policy maker to follow the office-seekers' strategy, an assumption is needed about the voters' belief if the policy maker (unexpectedly) repeals a policy. I assume that if the policy maker repeals a policy, voters conclude that the policy has been a failure, and adjust the probability that the incumbent is competent to $\hat{\pi}_{r}^{I}$ given by (4). Given this assumption about out-of-equilibrium beliefs, continuing a policy after observing that the policy is a success is optimal for the incumbent if:

$$
2 b_{1}+\left[G\left(\pi^{I}\right)-G\left(\hat{\pi}_{r}^{I}\right)\right]\left[X_{2}+\left(\hat{\pi}_{c}^{I}-\pi_{e}^{O}\right)(p-q) b_{2}\right]>0
$$


which is always satisfied. ${ }^{6}$ Condition (7) has the same interpretation as condition (5). The only difference is that voters' prior belief about the incumbent's competence is no longer affected by the decision to continue the implemented policy. Continuing a policy after observing that the policy is a failure is optimal for the incumbent if:

$$
-c_{1}+\left[G\left(\pi^{I}\right)-G\left(\hat{\pi}_{r}^{I}\right)\right]\left[X_{2}+\left(\hat{\pi}_{r}^{I}-\pi_{e}^{O}\right)(p-q) b_{2}\right]>0
$$

Condition (8) holds if $X_{2}$ is sufficiently high. Then, the incumbent incurs the cost of continuing a policy failure rather than facing a lower probability of reelection stemming from a decision to repeal the implemented policy. Hence, if the incumbent cares sufficiently about holding office relative to voters' welfare, he never repeals a policy. The office seekers' strategy is a Perfect Bayesian equilibrium strategy if condition (8) is satisfied.

\subsection{Equilibrium in Mixed Strategies}

If neither condition (6) nor condition (8) are satisfied, i.e. if:

$$
\frac{c_{1}}{G\left(\hat{\pi}_{c}^{I}\right)-G\left(\hat{\pi}_{r}^{I}\right)}<X_{2}+\left(\hat{\pi}_{r}^{I}-\pi_{e}^{O}\right)(p-q) b_{2}<\frac{c_{1}}{G\left(\pi^{I}\right)-G\left(\hat{\pi}_{r}^{I}\right)}
$$

a Perfect Bayesian Equilibrium in pure strategies does not exist. ${ }^{7}$ For these parameter values,

\footnotetext{
${ }^{6} \mathrm{As}$ in (5) and (6), the second term in (7) and (8) is positive unless the incumbent expects that he does not want to run for reelection at the end of period 1 . Then, the incumbent's optimal strategy is the socially efficient strategy spelled out in the previous section.

${ }^{7}$ Besides the pure strategies examined in the previous two subsections, two other pure strategies exist: the pure strategy in which the implemented policy is always repealed, and the pure strategy in which the policy is continued if it is a failure and repealed if it is a success.
} 
it holds that:

i) if voters believe that the policy maker follows the socially efficient strategy, the policy maker has an incentive to continue unsuccessful policies;

ii) if voters believe that the policy maker follows the office seekers' strategy, the policy maker has an incentive to repeal unsuccessful policies.

This inconsistency between the voters' beliefs and the incumbent's incentives stems from the difference between the two equilibrium strategies in voters' beliefs about the policy maker's competence after observing that a policy is continued. If voters believe that the incumbent plays the socially efficient strategy, voters adjust the prior probability that the policy maker is competent upwardly after observing that a policy is continued. If voters believe that the incumbent plays the office-seekers' strategy, continuing a policy does not affect the incumbent's reputation, since he always continues a policy. Therefore, the (opportunity) cost for the incumbent of repealing a policy is higher when voters believe that the incumbent plays the socially efficient strategy than when they believe that he follows the office-seekers' strategy. Hence, an incumbent may prefer to continue a policy failure if voters believe that he would never do so, while he prefers to repeal the policy if voters expect him never to repeal a policy.

For parameter values such that (9) holds, Perfect Bayesian Equilibria in mixed strategies exist in which successful policies are always continued and policy failures are continued with probability $0<\gamma<1$ and repealed with probability $(1-\gamma)$. If voters believe that the incumbent follows this mixed strategy, and the implemented policy is continued, they update the prior probability that the incumbent is competent to:

Under a mild assumption about out-of-equilibrium beliefs, these strategies are always dominated by the strategies discussed above. 


$$
\hat{\pi}_{c m}^{I}=\frac{\pi^{I}[p+(1-p) \gamma]}{\pi^{I}[p+(1-p) \gamma]+\left(1-\pi^{I}\right)[q+(1-q) \gamma]} .
$$

It is easy to show that $\pi^{I}<\hat{\pi}_{c m}^{I}<\hat{\pi}_{c}^{I}$. Hence, voters adjust the prior probability that the incumbent is competent in upward direction after observing that the policy is continued, but to a less extent than under the socially efficient strategy. If the incumbent repeals the policy, voters infer that the policy is a failure and update the prior probability that the incumbent is competent to $\hat{\pi}_{r}^{I}$ given by (4).

Given these beliefs, the incumbent prefers continuing to repealing a successful policy if:

$$
2 b_{1}+\left[G\left(\hat{\pi}_{c m}^{I}\right)-G\left(\hat{\pi}_{r}^{I}\right)\right]\left[X_{2}+\left(\hat{\pi}_{c}^{I}-\pi_{e}^{0}\right)(p-q) b_{2}\right]>0
$$

which always holds (see the discussion in the previous subsections). If the policy is a failure, continuing the policy with probability $\gamma$ and repealing the policy with probability $(1-\gamma)$ can only be part of an equilibrium strategy if the incumbent is indifferent between continuing and repealing the policy, given the voters' belief. Otherwise, the incumbent would always find it optimal to continue or repeal the policy. The incumbent is indifferent between continuing and repealing a policy failure if:

$$
X_{2}+\left(\hat{\pi}_{r}^{I}-\pi_{e}^{O}\right)(p-q) b_{2}=\frac{c_{1}}{G\left(\hat{\pi}_{c m}^{I}\right)-G\left(\hat{\pi}_{r}^{I}\right)} .
$$

where $\hat{\pi}_{c m}^{I}$ is given by (10). Comparing (12) and (9), and using (10), it follows that for all parameter values for which condition (9) holds, a unique value of $\gamma$ exists such that the incumbent is indifferent between continuing and repealing a policy after observing that the policy is a failure. Hence, for the intermediate cases described by (9), a Perfect Bayesian 
Equilibrium in mixed strategies exists wherein the incumbent always continues a policy if it is a success, and only with a certain probability repeals a policy if it is a failure.

\section{Conclusions}

In this paper, I have shown that policy makers may find it optimal to stick to inefficient policy decisions for the purpose of reelection. I have argued that repealing a policy is a bad signal to voters about the policy maker's competence in designing policies. Imperfect information about policy effects plays a major role in the analysis. First, I have assumed that before implementation of a policy, the policy maker does not know with certainty whether the policy he has designed will be a success or a failure, even if the policy maker is highly competent in designing policies. Hence, policy failures sometimes occur, and the more often, the less competent is the policy maker. Second, I have assumed that voters have imperfect information about the effect of policies, both before and after implementation. This assumption implies that the policy maker's decision to repeal or continue a policy affects the voters' belief about the policy's effect, and thus affects the voters' belief about the policy maker's competence. If the policy maker cares sufficiently about holding office relative to voters' welfare, he prefers continuing to repealing an inefficient policy, because repealing a policy implies a costly worsening of electoral prospects.

Since the key argument rests on an informational advantage by the incumbent, a natural extension of the present study is to examine the incentives other players in the political process might have to obtain information, and to provide information to voters about the effects of implemented policies. One might expect that members of parliament may play an important role here as one of their main tasks is to monitor the incumbent. However, the incentives to provide correct information to voters may be weak if members of parliament are 
predisposed in the incumbent's (or future opponent's) favour, for example because they have policy preferences similar to (or opposing to) the incumbent's preferences. This renders their messages soft information. Another interesting extension of the present study could be to examine whether candidates, before knowing the election outcome, are willing to commit to policy evaluation by an "independent" committee.

\section{Appendix}

In this appendix, I show that the results carry over to the case wherein voters receive a noisy signal about the effect of the implemented policy. I assume that voters observe the noisy signal before the incumbent makes a decision on continuation of the policy, and that the incumbent also sees the noisy signal observed by voters. If the policy is a success, voters observe a signal of success with probability $1 / 2<s<1$ and a signal of failure with probability $(1-s)$. If the policy is a failure, voters observe a signal of failure with probability $1 / 2<f<1$ and a signal of success with probability $(1-f)$. After observing a signal of success, voters update their prior belief about the policy maker's competence to:

(A1)

It is straightforward to show that $\pi^{I}<\hat{\pi}_{s}^{I}<\hat{\pi}_{c}^{I}$. After observing a signal of failure, voters update their prior belief about the policy maker's competence to:

$$
\hat{\pi}_{f}^{I}=\frac{\pi^{I}[p(1-s)+(1-p) f]}{\pi^{I}[p(1-s)+(1-p) f]+\left(1-\pi^{I}\right)[q(1-s)+(1-q) f]} .
$$

It is straightforward to show that $\hat{\pi}_{r}^{I}<\hat{\pi}_{f}^{I}<\pi^{I}$. 
Suppose that voters have observed a signal of success. Following the discussion in subsection 3.1, the socially-efficient strategy is a Perfect Bayesian equilibrium strategy if condition (6) holds. Following the discussion in subsection 3.2, the office-seekers' strategy is a Perfect Bayesian equilibrium strategy if:

$$
-c_{1}+\left[G\left(\hat{\pi}_{s}^{I}\right)-G\left(\hat{\pi}_{r}^{I}\right)\right]\left[X_{2}+\left(\hat{\pi}_{r}^{I}-\pi_{e}^{O}\right)(p-q) b_{2}\right]>0
$$

Condition (A3) is similar to (8) except for the probability of reelection if the policy is continued: instead of $G\left(\pi^{I}\right)$, the incumbent faces probability $G\left(\hat{\pi}_{s}^{I}\right)$ of reelection if he continues the policy. Since $\hat{\pi}_{s}^{I}>\pi^{I}$, the office-seekers' strategy is an equilibrium strategy for a larger set of parameter values if voters have observed a noisy signal of success compared to the case where voters remain completely uninformed about the effect of the implemented policy. The reason is that when voters have observed a noisy signal of success, they adjust the prior probability that the policy maker is competent in upward direction. Hence, the decrease in the probability of reelection after deciding to repeal the policy, and thus the cost of repealing the policy for the policy maker, is larger when voters have seen a noisy signal of success than when voters have not received a noisy signal. If neither condition (6) nor condition (A3) are satisfied, Perfect Bayesian Equilibria in mixed strategies exist in which successful policies are always continued and policy failures are continued with probability $0<\gamma<1$ and repealed with probability $(1-\gamma)$. If voters believe that the incumbent follows this mixed strategy, and the implemented policy is continued, they update the prior probability that the incumbent is competent to:

(A4)

$$
\hat{\pi}_{s c m}^{I}=\frac{\pi^{I}[p s+(1-p)(1-f) \gamma]}{\pi^{I}[p s+(1-p)(1-f) \gamma]+\left(1-\pi^{I}\right)[q s+(1-q)(1-f) \gamma]}
$$


Following the discussion in subsection 3.3, the equilibrium value of $\gamma$ is implicitly defined by:

(A5)

$$
X_{2}+\left(\hat{\pi}_{r}^{I}-\pi_{e}^{O}\right)(p-q) b_{2}=\frac{c_{1}}{G\left(\hat{\pi}_{s c m}^{I}\right)-G\left(\hat{\pi}_{r}^{I}\right)} .
$$

Along similar lines of reasoning, it is straightforward to derive the Perfect Bayesian equilibrium strategies for the case in which voters have observed a noisy signal of failure. Again, the socially efficient strategy is an equilibrium strategy if (6) holds. The officeseekers' strategy is an equilibrium strategy for a smaller set of parameters if voters have observed a noisy signal of failure compared to the case where voters remain completely uninformed about the effect of the implemented policy. A Perfect Bayesian Equilibria in mixed strategies exist for a larger set of parameters. 


\section{References}

Alesina, A., and A. Cukierman (1990), The Politics of Ambiguity, Quarterly Joumal of Economics, 105 , p. 829-850.

Alesina, A., and A. Drazen (1991), Why Are Stabilizations Delayed?, American Economic Review, 81, p. 1170-1188.

Cadot, O., and B. Sinclair-Desgagné (1992), Prudence and Success in Politics, Economics andPolitics, 4, p. 171-189.

Fernandez, R., and D. Rodrik (1991), Resistance to Reform: Status Quo Bias in the Presence of Individual- Specific Uncertainty, American Economic Review, 81, p. 1146-1155.

Glazer, A., and B. Grofman (1989), Why Representatives Are Ideologists Though Voters Are Not, Public Choice, 61, p. 29-39.

Glazer, A., and R. Hassin (1998), Government Failure in Evaluating Programs, Public Choice, 94 , p. 105-115.

Harrington, J.E., Jr. (1993), Economic Policy, Economic Performance, and Elections, American Economic Review, 83, p. 27-42.

Howitt, P., and R. Wintrobe (1995), The Political Economy of Inaction, Journal of Public 
Economics, 56, p. 329-353.

Letterie, W., and O.H. Swank (1998), Economic Policy, Model Uncertainty, and Elections, Economics and Politics, 10, p. 85-103.

Rogoff, K. (1990), Equilibrium Political Budget Cycles, American Economic Review, 80, p. 21-36.

Schultz, C. (1996), Polarization and Inefficient Policies, Review of Economic Studies, 63, p. 331-344.

Schultz, C. (1999), Elections, Uncertainty, and Policy Distortions, mimeo, University of Copenhagen.

Swank, O.H. (1998), Towards an Economic Theory of Party Ideology, European Journal of Political Economy, 14, p. 223-240.

Swank, O.H. (1999), Does Political Competition Give Political Agents Incentives to Create an Efficient Bureaucratic System?, mimeo, Erasmus University Rotterdam.

Wirl, F. (1991), The Political Economics of Wackersdorf: Why Do Politicians Stick to Their Past Decisions?, Public Choice, 70, p. 343-350. 